\title{
Rekindle dynamics: validating the pressure on wildland fire suppression resources and implications for fire management in Portugal
}

\author{
A. P. Pacheco ${ }^{1}$, J. Claro $^{1} \&$ T. Oliveira ${ }^{2}$ \\ ${ }^{1}$ INESC TEC (formerly INESC Porto) and Faculdade de Engenharia, \\ Universidade do Porto, Portugal \\ ${ }^{2}$ Forest Protection, grupo Portucel Soporcel, Portugal
}

\begin{abstract}
Rekindles can represent a high burden on wildland fire suppression resources, but despite the relevance of this phenomenon in Portugal, related research is still scarce. Seeking to contribute to address this gap, the purpose of this study was to organize and provide an overview of the problem of rekindles in Portugal, and to verify whether evidence exists that the high proportion of rekindles in Portugal is related to the double duty of Portuguese firefighters to perform initial attack and mop-up operations. Our study included informal meetings, formal recorded interviews, dispatch centre visits, actual rekindle observation, and an analysis of the National Forest Authority database. From the study of genealogies of rekindles, we concluded that $17.2 \%$ additional forest fires (rekindles in successive generations) had their origin in only $7.4 \%$ of primary fires. Through linear regression analysis, we found that their proportions increase in days with more occurrences, preliminarily supporting the hypothesis of premature abandonment of mop-up operations, as a result from the pressure to immediately attack starting fires by the same crews. A more detailed analysis of two representative districts highlighted specific organizational and natural challenges to successful mop-up efforts and provided further evidence of the hazardousness of rekindles.
\end{abstract}

Keywords: wildfire, rekindle, mop-up operations, reburn, initial attack, suppression. 


\section{Introduction}

There are few natural phenomena with the scope and complexity of a forest fire (Van Wagner [1]). An intricate part of that phenomena are rekindles, or reignitions, that reburn an area over which a previous fire has passed, but has left fuel that later ignites due to latent heat, sparks, or embers (NWCG [2]). Throughout the 2010 summer, Portugal had 14,551 primary wildfires, of which $17.2 \%$ rekindled into an additional 2,497 fires, leading to a total of 17,048 . That summer accounted for $94.7 \%$ of the wildland annual burnt area of 132,241 ha. However these figures may be worse. Several authors suggest that the amount of rekindled forest fires is higher than officially reported (ANIF [3], Lourenço and Rainha [4]). Expert-judgment elicitation in our interviews points to the double. Even assuming that the available information is correct, there are too many rekindles (Beighley and Hyde [5]). This is a concerning situation that has gotten worse over the years (ANIF [3]), and results from ineffective mop-up operations (ANIF [3], Lourenço and Rainha [4], Beighley and Hyde [5], ISA [6], Lourenço [7], Murdock et al. [8]) despite the effective initial attack (ANIF [3], Lourenço and Rainha [4], Lourenço [7]). Although there is a danger of fatalities during the mop-up stage (Alexander et al. [9]), this danger is even higher in a rekindle scenario (NWCG [10]). Finally, this ineffective mop-up and lack of surveillance (Lourenço [7]) results in rekindles that often become large fires (ANIF [3], Lourenço and Rainha [4], Lourenço [7]). These are usually bigger than the wrongly judged extinguished primary fire, with large burnt areas and considerable damage (ANIF [3]), even when the initial perimeter was just tens of meters (Lourenço and Rainha [4]).

During the suppression effort, as soon as the fire slows to a point where it can be fought safely, the fire crews establish control lines around the perimeter of the fire. They solidify it and gradually work from the perimeter towards the interior of the fire, extinguishing flames farther and farther from the fire's edge (Martell [11]). Once the fire is declared under control, the essential job of mopping up begins; afterwards, the area must be patrolled before it is declared truly "out" (Murdock et al. [8], Martell [11], Alexander [12]). Done along the fire control line, mop-up involves eliminating all hot areas and removing burning material. Hot spots can be found by visible signs, smoke smell, audible signs or by touch. A small spark left near a control line can cause a later rekindle (Murdock et al. [8]). This mop-up stage may proceed for days or weeks (Martell [11]). Being an exceedingly time-consuming stage, it is also very costly (González-Cabán [13]). Several studies found considerable regional variation in costs, significantly influenced by site-specific factors. Physical site characteristics, however, do not fully explain the observed variation in mop-up costs (Donovan and Brown [14]). Thus natural (weather conditions, spatialtemporal concentration) and organizational (human resources and equipment management) factors must be considered (AFN [15]). This is the case of Portuguese mainland, where across the 18 districts the proportions of rekindles varied from zero to $85 \%$, with half of the districts featuring proportions above $9.3 \%$. 
After the disastrous fires of 2003 (Fernandes [16]), repeated two years later, the government commissioned a technical strategy (ISA [6]) to address this problem. In 2006, a modified version (shifting the emphasis from prevention to an increase in suppression capability) was approved and published (CM [17]) as the national strategy for forest protection against fires (Beighley and Hyde [5]). The plan recognizes the impact of rekindles and establishes mitigation as one of the priorities, with a goal of $1 \%$ by 2010 defined as an accepted value for the rekindle rate (Oliveira [18]). However, this goal was not ever achieved (AFN [15]) and could be too ambitious. Compared, for instance, to the USA 2004-2008 rekindle annual averages, which vary between 2 and 6\% (Ahrens [19]), it is known that the local rate is still higher (Pacheco [20]).

Many of these rekindles occur in inaccessible areas where fires are not properly mopped up (Beighley and Hyde [5]). Fire lines are often constructed using existing roads (Lourenço and Rainha [4], Beighley and Hyde [5]) or near houses (Lourenço and Rainha [4]). Between these infrastructures and the burnt areas remain fuels with low moisture due to the pre-heating, which later may rekindle (Lourenço and Rainha [4]). Meanwhile, mop-up is made exclusively with water in most cases, without the appropriate tools to consolidate the perimeter safely (ANIF [3], Lourenço and Rainha [4], Beighley and Hyde [5]). In short, the lack of specialized crews in firefighting with hand tools is a huge tactical limitation (ISA [21]). In fact, mop-up should be done with hand tools, working with water as a complement (ANIF [3], Beighley and Hyde [5]). Tools are used to rake, chop, scrape and dig out hot fuels (Murdock et al. [8]), making a trench up to the mineral soil (Oliveira [18]), or regolith, where water does not penetrate until a discontinuity is created (Lourenço and Rainha [4]). Water, if available, is used to cool down these fuels mixed with hand tools in the hot spots (Murdock et al. [8]). Also with hand tools or machines, it is critical to create a break in continuity between the contiguous burnt and non-burnt areas (Lourenço and Rainha [4]). Otherwise, hot spots may not be extinguished and can rekindle (Murdock et al. [8]).

The high level of rekindles may indicate that there were problems in post-fire management and active surveillance (AFN [15]). Some authors suggest the need for specialized extended attack hand crew brigades (Beighley and Hyde [5]) and complementary crews properly trained in mop-up operations, in particular if spatiotemporal concentration of primary fires occurs (ISA [6]). In practice, the crews that need to remain on the mop-up are often the same that need to be available for new fires - primary or rekindled. This double-duty weakens the system. It is pointed to as one of the reasons why the percentage of rekindles is so high. In other words, firefighters are often pulled away from a fire prematurely, to respond to new initial attack demands (Beighley and Hyde [5]).

This research analyses the latter hypothesis. In days with a higher number of occurrences, the pressure to abandon mop-up operations prematurely may increase. This leads to future rekindles that further increase the number of active fires. We study rekindle genealogies and use linear regression across Portuguese districts. The results can provide useful information that could enhance the effectiveness of suppression activities. The paper is organised as follows. In the 
next section, we present data sources, describe the regression and briefly explain how we constructed the rekindle genealogies and the number of daily active fires. Subsequently, we present the results, highlighting some of their aspects. The final section discusses main points, and offers some conclusions.

\section{Data and methods}

For this study we use data kindly provided by Autoridade Florestal Nacional (AFN). This wildfire dataset, although having undergone several changes throughout the years, has been relatively stable in the last 12 years. The current version gathers information regarding the location of the fire, date and time (i.e. alert, ignition and extinction), burnt area, type of event, and causes. The events could be false alerts, fires in agricultural lands, or wildland fires (forests and shrublands). Information about the nature of the fire (single or reignition) is recorded since 1984 (Pereira et al. [22]). We focused our attention on 2010 because this is the first year for which appropriate data on rekindles is available. For instance, it is now possible to know, for each rekindle, the specific fire whose bad mop-up originated it.

The country mainland is divided in 18 main administrative regions (districts), their corresponding municipalities ( 278 counties, ) and 4,050 parishes. There are significant geomorphologic, climatic and demographic differences between the northern and southern parts of Portugal (Pereira et al. [22]). Fire policies, suppression and prevention efforts are organized at the district level. They are therefore too heterogeneous, and we chose them as unit of analysis.

Rekindles represent a high burden on suppression resources. Our goal (and hypothesis) is to find whether there is any evidence that in days with more ignitions, the firefighters are compelled to prematurely abandon the fire mop-up operations, thus promoting even more rekindles. In other words, we want to know if the high number of rekindles results from the pressure to immediately combat all the new fires, preventing them from becoming big fires. To accomplish this, we conducted a linear regression analysis study, considering two variables. We consider the explanatory variable as the number of fires that were simultaneously fought in each day (active fires). For the first component of the dependent variable, we count the number of fires with bad mop-up in that same day, i.e., the fires erroneously declared extinct and origin of some later rekindle. However, because it is expected that bad mop-ups increase with adverse climatic conditions and the number of fires in each day, we divided this component by the number of active fires in that day. To count the number of fires with bad mop-up in a particular day, we performed a detailed treatment of the database to uncover the genealogies of rekindles, identifying for each rekindle the bad mop-up that originated it. We used Microsoft Excel $^{\circledR}$ and MapPoint Europe $2011^{\circledR}$ for the pivot tables and maps, IBM SPSS Statistics $19^{\circledR}$ for descriptive statistics, and STATA/IC $12^{\circledR}$ for regression analysis. 


\section{Results}

\subsection{Overview of forest fires and rekindles in Portugal}

From the point of view of the suppression system, a false alert or a fire in agricultural lands produces the same pressure as a wildland fire (Pacheco [20]). Firefighters do not know beforehand which type of event they are being called to, and they need to get to the site as fast as possible. For this reason, we include all these events, and not only forest fires, in our analysis. Also, because of the temporal concentration of fires in Portugal (Table 1), we focus on the critical period between July and August called the "Charlie" phase.

Table 1: $\quad$ Number of occurrences, rekindles and burnt area (Summer, 2010).

\begin{tabular}{|l|r|r|r|r|r|r|}
\cline { 2 - 4 } \multicolumn{1}{c|}{} & \multicolumn{3}{c|}{ All events } & \multicolumn{3}{c|}{ Wildland fires } \\
\cline { 2 - 5 } \multicolumn{1}{c|}{} & \multirow{2}{*}{ All year } & \multicolumn{1}{c|}{ July - August } & \multirow{2}{*}{ All year } & \multicolumn{2}{c|}{ July - August } \\
\cline { 3 - 7 } \cline { 5 - 7 } & & \multicolumn{1}{c|}{ All } & Time data & & \multicolumn{1}{c|}{ All } & Time data \\
\hline Wildland burnt area (ha) & 133,091 & 125,859 & 125,688 & 132,241 & 125,173 & 125,003 \\
\hline Total burnt area (ha) & 141,840 & 133,487 & 133,294 & 139,121 & 131,716 & 131,545 \\
\hline Events/fires & 32,357 & 24,036 & 23,232 & 22,026 & 17,048 & 16,965 \\
\hline Rekindles & 2,733 & 2,543 & 2,532 & 2,687 & 2,497 & 2,486 \\
\hline
\end{tabular}

For some chains of successive rekindled fires, the database holds information about the burnt area for each individual rekindled fire. But for most cases, because of measurement difficulties when there is a high number of active fires, only the total area measured at the end is registered, in the ancestor fire (the first fire whose bad mop-up starts that particular chain), with all the successive rekindles attributed a zero burnt area. For this reason, we were unable to directly assess the impact of bad mop-ups on burnt area. However, an examination of the districts with more than (on average) five new ignitions per day (Figure 1) provides some evidence of the expert-judgment assessment that most of burnt area comes from rekindles. Indeed, the proportion of rekindles to active events (bubble area) appears to be greater in districts with more burnt area.

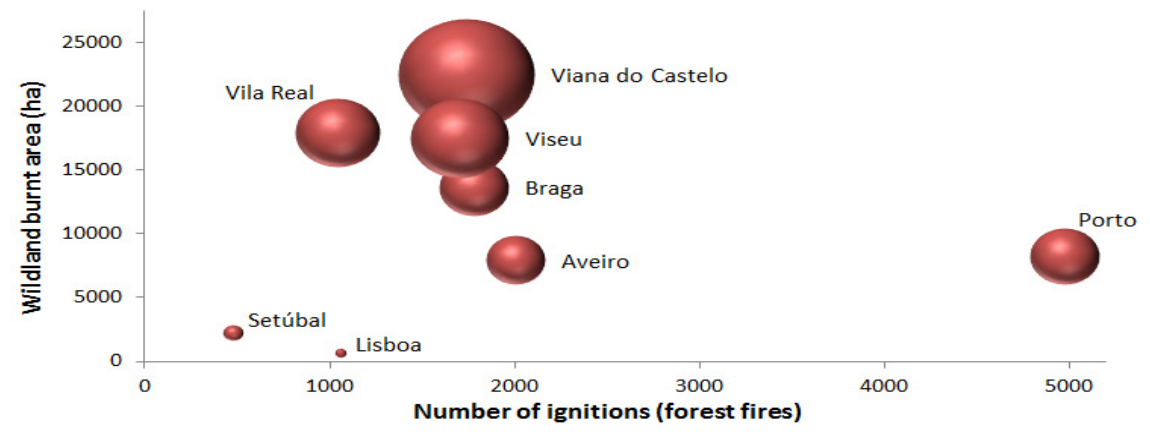

Figure 1: Relationship between ignitions, burnt area, and rekindles; bubble area represents the proportion of rekindles to forest fires. 
Figure 2 shows the density of rekindles (number of rekindles per $1000 \mathrm{~km}^{2}$ of forest area) in each municipality. In short, rekindles are spatially concentrated in seven districts (in the north near the coastline): Aveiro, Braga, Coimbra, Porto, Viana do Castelo, Vila Real and Viseu.

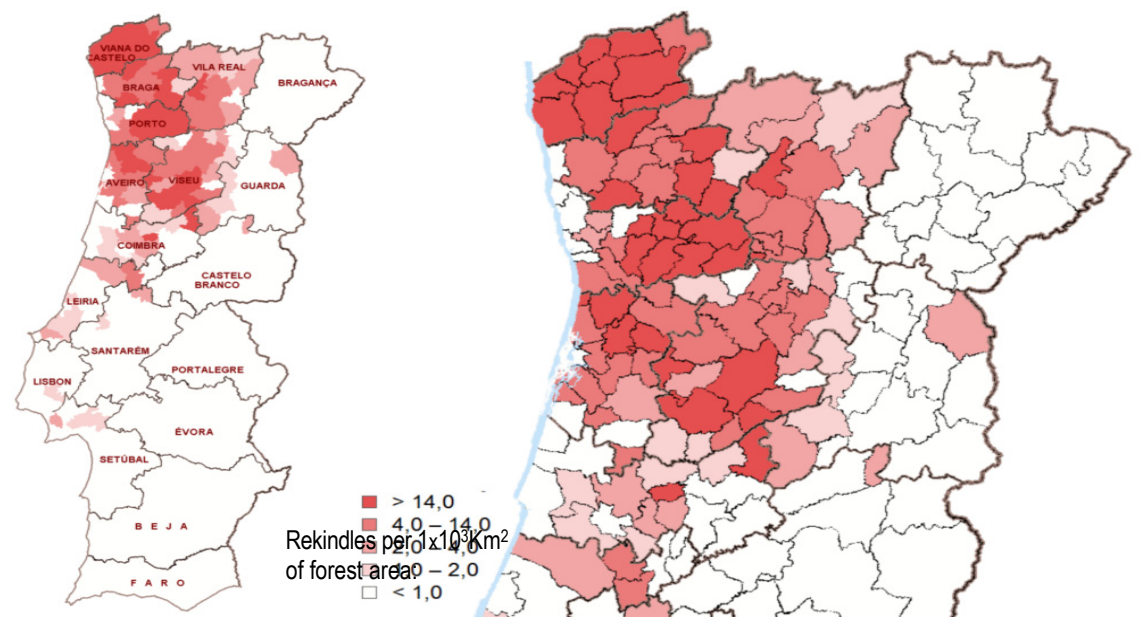

Figure 2: Spatial concentration of rekindles in mainland Portugal.

\subsection{Active events}

To determine the number of simultaneous (active) events, the alert and finish times of each event are required. This forced us to remove from our analysis 171 fires, less than $0.14 \%$ of all the data (see Table 1 ). Processing the information in the database with the help of pivot tables, and using a daily balance of entries and exits, we were able to compute the number of fires actually being fought each day. Half of the districts have more than nine active fires, with the presence of extremes quite superior to the mean, and outliers in four of them (Figure 3).

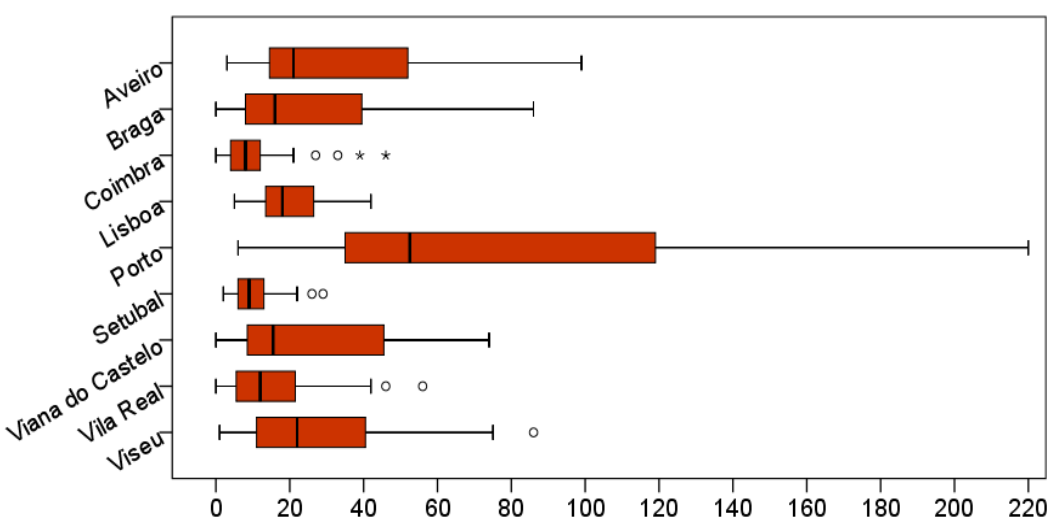

Figure 3: Box plot of active fires in the more devastated districts. 
On any given day, there will usually be a difference between new and active events, as a consequence of fire durations that are higher than one day (Figure 4). These numbers show very high oscillations along the season, across all districts.

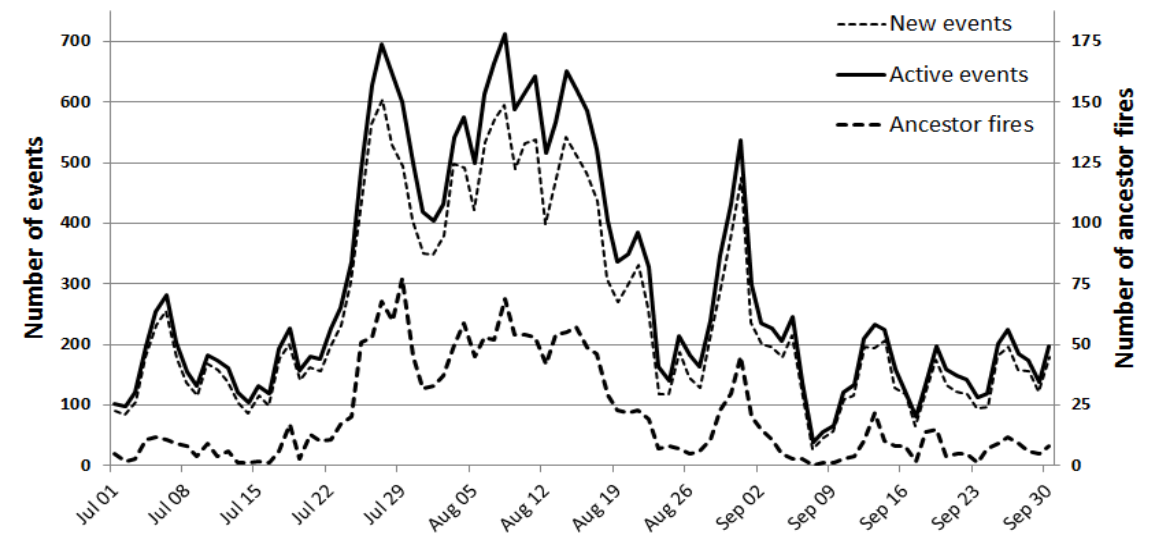

Figure 4: Daily panorama of new and active events, and primary bad mop-ups.

\subsection{Bad mop-ups and rekindles}

To uncover the genealogy of each rekindle, we started by identifying all the ancestor fires (new fires with bad mop-ups). We extended this analysis to the whole year because a restriction to the summer period would exclude bad mopups in the final days of June. In Portugal, the year begins in the coldest season without any active fires. Table 2 shows an interval of 1 to 28 rekindles originated from ancestor fires. For the 786 ancestors with one rekindle, no additional data processing was required. For the remaining 479 chain events, we collected and identified all the intermediate fires with bad mop-ups in the chain. The diagram at the bottom of Table 3 graphically outlines this idea that some rekindles also rekindle and must be considered as part of the set of bad mop-ups.

Table 2: $\quad$ Ancestor fires organized by the number of rekindles originated.

\begin{tabular}{|c|c|c|c|c|c|c|c|c|c|c|c|c|c|c|c|c|c|c|c|}
\hline $\begin{array}{c}\text { Times } \\
\text { rekindled }\end{array}$ & 1 & 2 & 3 & 4 & 5 & 6 & 7 & 8 & 9 & 10 & 11 & 12 & 13 & 15 & 16 & 18 & 22 & 25 & 28 \\
\hline $\begin{array}{c}\text { Ancestor } \\
\text { events/fires }\end{array}$ & 786 & 189 & 100 & 65 & 39 & 20 & 13 & 13 & 10 & 8 & 5 & 4 & 4 & 1 & 3 & 2 & 1 & 1 & 1 \\
\hline Rekindled & 786 & 378 & 300 & 260 & 195 & 120 & 91 & 104 & 90 & 80 & 55 & 48 & 52 & 15 & 48 & 36 & 22 & 25 & 28 \\
\hline
\end{tabular}

We built an SQL query to identify, for each chain, the groups of fires with the same geographic coordinates, excluding the fires with successful mop-ups (whose end occurs after any of the beginnings in that group). As a result, we identified an additional 855 bad mop-ups, leading to an annual total of 2,120 
(Table 3). Figure 5 illustrates this process for an extreme case in the district of Viseu, for which $99.3 \%$ of the burnt area was due to successive rekindled fires.

Table 3: $\quad$ Results from the analysis of rekindle genealogies.

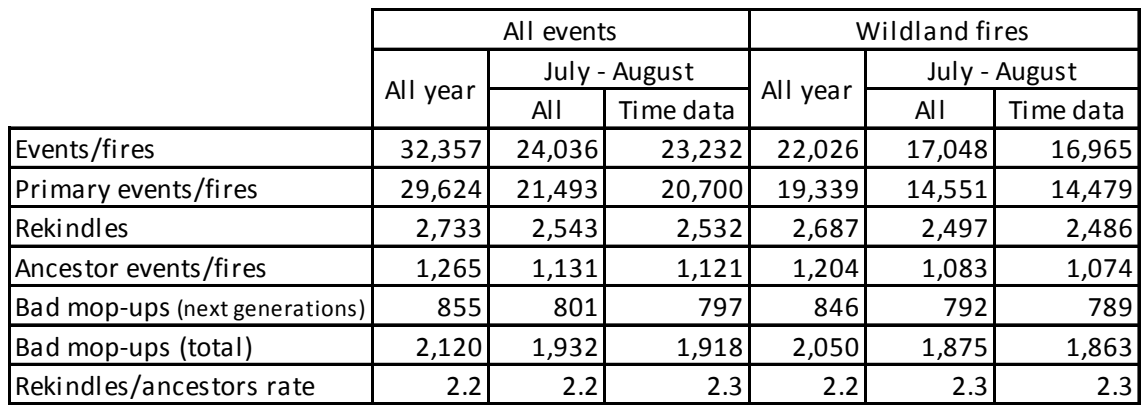

Events/fires which occurred between July and August with sufficient data (start and finish)

\begin{tabular}{|l|c|c|}
\hline \multicolumn{2}{|c|}{ Primary events/fires } & \multicolumn{2}{c|}{ Rekindles } \\
\cline { 2 - 3 } & Ancestor events/fires & Bad mop-ups \\
\hline \multicolumn{2}{|c|}{ Total bad mop-ups }
\end{tabular}

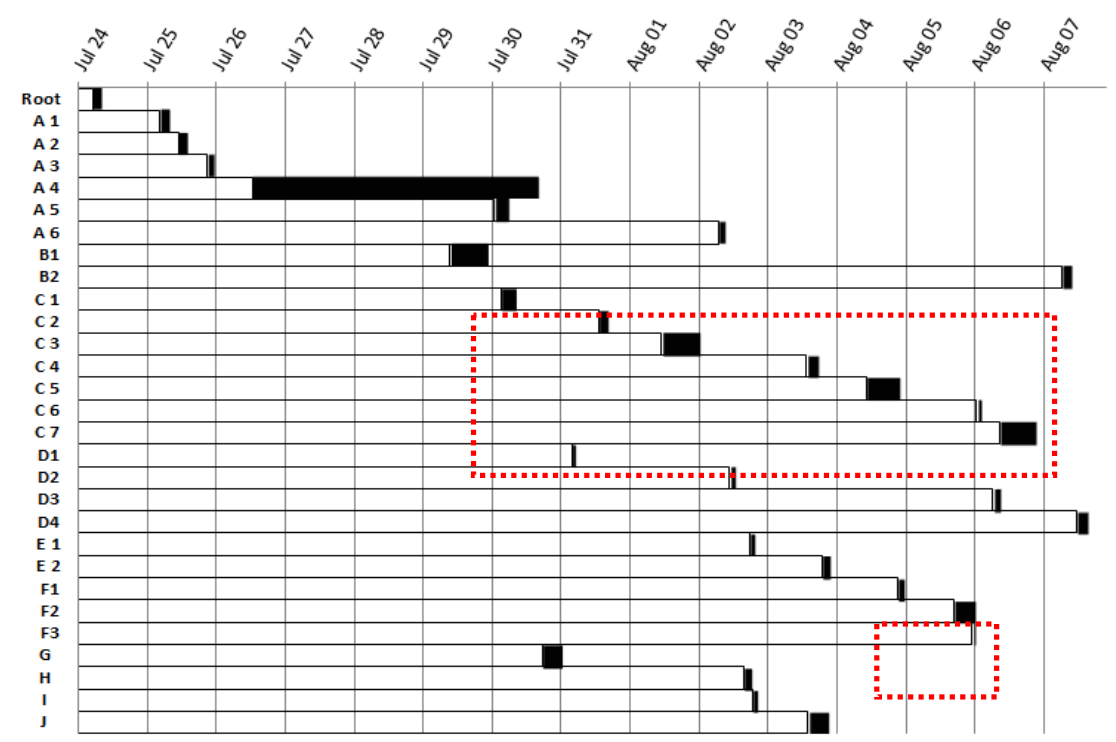

Figure 5: A case study of a tree of 28 rekindles of the same fire in Viseu with seven sub-chains (letters A to J), and seventeen intermediate fires with a bad mop-up; notice that fires F2 and F3 occur at the same time and thus are not counted as bad mop-ups.

We excluded from our analysis districts with few or no rekindles. A criterion of considering only districts with a daily average of rekindles above 0.5 
concentrated the analysis on seven districts: Aveiro, Braga, Coimbra, Porto, Viana do Castelo, Vila Real and Viseu.

\subsection{Regression analysis}

With the data on proportion of bad mop-ups and number of active fires for the selected districts, we were able to perform our regression analysis study. The correlation coefficients, as well as the p-values for the regressions, are shown on Table 4. The results provide statistical support to our hypothesis that the proportion of bad mop-ups increases with the number of active events. The only exception is the district of Viana do Castelo, which is discussed in the final section of this paper.

Table 4: $\quad$ Regression results for the seven selected districts.

\begin{tabular}{|l|c|c|c|c|c|c|c|}
\cline { 2 - 8 } \multicolumn{1}{c|}{} & $\mathbf{R}$ & Prob > F & $\begin{array}{c}\text { Active events } \\
\text { (daily mean) }\end{array}$ & $\begin{array}{c}\text { New events } \\
\text { (daily mean) }\end{array}$ & Ancestors & $\begin{array}{c}\text { Bad } \\
\text { mop-ups }\end{array}$ & Rekindles \\
\hline V. Castelo & +0.1575 & 0.1406 & 26 & 21 & 311 & 580 & 796 \\
\hline Coimbra & +0.2405 & 0.0224 & 9 & 9 & 35 & 48 & 63 \\
\hline Aveiro & +0.2607 & 0.0121 & 34 & 31 & 125 & 149 & 174 \\
\hline Braga & +0.2736 & 0.0108 & 26 & 22 & 110 & 148 & 205 \\
\hline Viseu & +0.4691 & 0.0000 & 27 & 23 & 136 & 312 & 410 \\
\hline Vila Real & +0.5120 & 0.0000 & 15 & 13 & 103 & 153 & 184 \\
\hline Porto & +0.7256 & 0.0000 & 79 & 63 & 220 & 431 & 581 \\
\hline
\end{tabular}

\subsection{Rekindle generations}

As Porto is the district with the highest correlation, we conducted a more detailed analysis of the rekindle dynamics inside this district. As shown in Figure 6 , in the first generation of 5,118 wildfires, 197 had bad mop-ups and thus rekindled $(3.85 \%)$. These 197 rekindles originated 500 additional fires $(254 \%$ more). 22 fires of that second generation (4.4\%) had again bad mop-ups and rekindled into 51 other fires $(232 \%$ more) on the third and successive rekindle generations. As a matter of fact, 551 wildfires could have been avoided if 197 primary fires had had a successful mop-up in first place. These rekindle/ancestor ratios of $254 \%$ and $232 \%$ are consistent with the national averages (see Table 3 ).

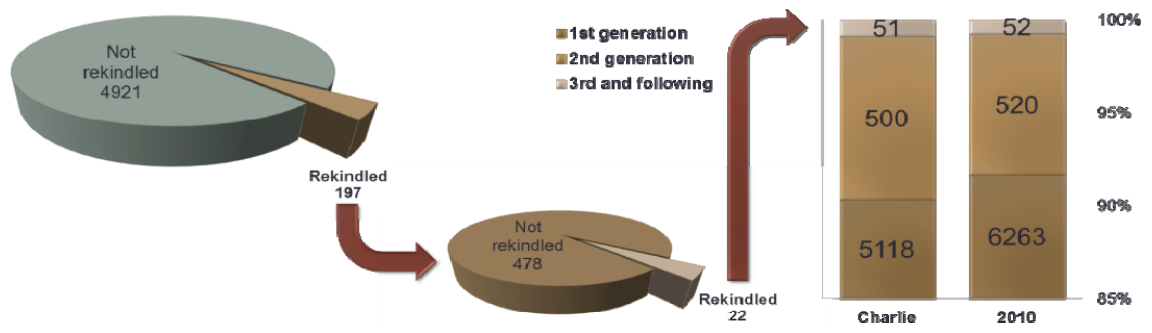

Figure 6: Rekindle genealogies in the district of Porto (Pacheco [20]). 
Finally, crossing the database of AFN and the database of the Dispatch Center of the district of Porto (CDOS Porto), which registers the assignment of suppression resources to each event, we determined that, on average, rekindles have initial and extended attacks longer than primary fires, $19.2 \%$ and $51.3 \%$ respectively (Pacheco [20]). This underlines the hazardousness of rekindles in the district of Porto, and provides further evidence of the impact of bad mop-ups on burnt area.

\section{Discussion and conclusions}

Among the districts with a relevant number of rekindles, only one - Viana do Castelo - did not present a statistically significant positive correlation between the proportion of bad mop-ups and the number of active fires. The plot of the relationship between the two variables (Figure 7) displays no discernible trend; however it shows very clearly a persistently very high proportion of bad mopups. In our contacts with experts, a key explanation that was put forward for this result was the fact that this is the district in the country with the lowest ability to mobilize volunteer firefighting efforts, which leaves mop-up activities permanently understaffed. Another potential cause is the fact that the district has a very large mountain area, where wildfires are more difficult to control, resulting in higher burnt areas and perimeters, and therefore higher probabilities of rekindling.
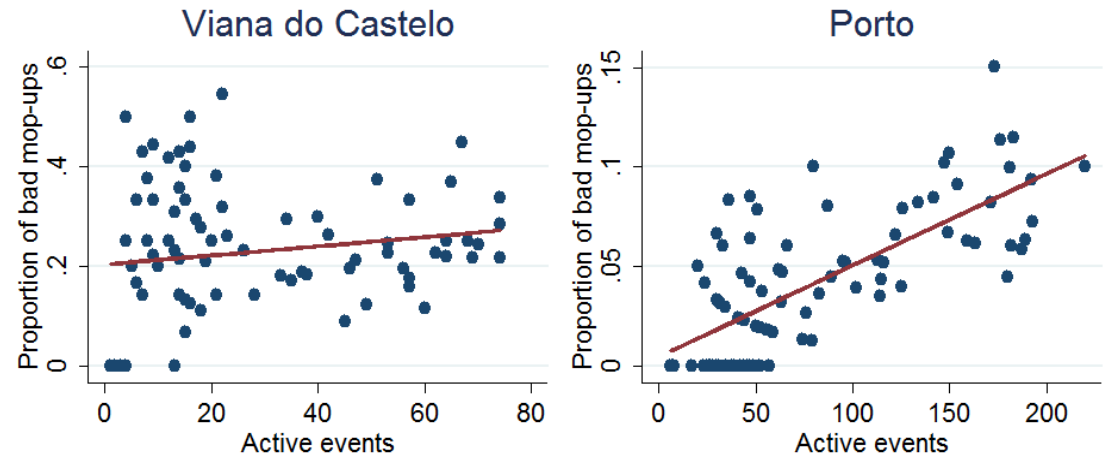

Figure 7: $\quad$ Plots of values and fitted values for Viana do Castelo and Porto.

The district where the effect of suppression pressure on bad mop-ups is clearer is the district of Porto. The correlation is high and the plot (Figure 7) shows a distinct trend of increase in the proportion of bad mop-ups with the increase in active events. The district of Porto has a historical trend of a very high number of forest fires, which remained through 2010, with a very high proportion of forest fires with a burnt area below 1 ha $-90.6 \%$ of the six thousand incidents (Pacheco [20]). This very high number of incidents puts a huge pressure on the suppression system, which not only works at constantly very high levels of capacity utilization, but also is constantly being requested for initial attack of new fires or rekindles. 
The research presented in this paper initially uses the literature review and the results of our fieldwork to identify, organize, and relate the set of physical, natural, technical and organizational factors that influence the occurrence of rekindles. We then use data analysis and descriptive statistics to present evidence of the size and impact of the problem of rekindles in Portugal. A key contribution of our work results from a simple linear regression analysis of the relationship between active events and the proportion of bad mop-ups to active events. A statistically significant positive relationship was found for six of the seven districts with a relevant number of rekindles. Finally, a more detailed view of rekindle dynamics in the districts of Viana do Castelo (the only district with a non-significant regression) and Porto (the district with the higher significant correlation) highlights specific organizational and natural challenges to a successful mop-up effort and provides further evidence of the hazardousness of rekindles. Among future work, we plan to extend this study to new data that is becoming available for more recent fire seasons, and analyse the performance of alternative organizational architectures for suppression efforts, with specialized teams assigned to the different suppression tasks.

\section{Acknowledgements}

This work is financed by the ERDF - European Regional Development Fund through the COMPETE Programme (operational programme for competitiveness) and by National Funds through the FCT - Fundação para a Ciência e a Tecnologia (Portuguese Foundation for Science and Technology) within project FIRE-ENGINE Flexible Design of Forest Fire Management Systems / MIT/FSE/0064/2009.

The authors are deeply grateful to Cândido Resende, Manuel Rainha, and Paulo Bessa, for their invaluable input and feedback on this research. They would also like to thank Rui Almeida, who was key in facilitating access to data, and Kristen Schell, for advice on the drafting of this paper.

\section{References}

[1] Van Wagner, C. E., "Fire behavior modelling - How to blend art and science." pp. 85-04, 1985.

[2] NWCG. "Glossary of wildland fire terminology," 5 March, 2012; http://www.nwcg.gov/pms/pubs/glossary/ (Archived by WebCite ${ }^{\circledR}$ at http://www.webcitation.org/65wjoO4i7).

[3] ANIF, Relatório Final ( $\mathrm{Vol}$ I), vol. I, Autoridade Nacional para os Incêndios Florestais, 2005.

[4] Lourenço, L., and Rainha, M., "As mediáticas 'mãos criminosas dos incendiários'e algumas das 'lições dos fogos florestais de 2005 em álbum fotográfico. Contributo para a desmistificação dos incêndios florestais em Portugal," Territorium, no. 13, pp. 71-82, 2006.

[5] Beighley, M., and Hyde, A. C., Systemic Risk and Portugal's Forest Fire Defense Strategy, 2009. 
[6] ISA, "Proposta técnica de Plano Nacional de Defesa da Floresta contra Incêndios," Volume I, 2005.

[7] Lourenço, L., "Incêndios florestais de 2003 e 2005. Tão perto no tempo e já tão longe na memória!," Colectâneas Cindínicas-Riscos Ambientais e Formação de Professores, vol. 7, pp. 19-91, 2007.

[8] Murdock, J. I., Borough, M. S., and Wasilla, A., Cross-training Standards for Structural and Forestry Personnel in Urban Interface Wildfires: One Alaskan Solution: National Fire Academy, 1999.

[9] Alexander, M. E., Mutch, R. W., and Davis, K. M., "Wildland fires: Dangers and survival," Wilderness Medicine, Auerbach, P. S., ed., pp. 286335: Elsevier, 2007.

[10] NWCG, Wildfire Origin and Cause Determination Handbook: National Wildfire Coordinating Group, Fire Investigation Working Team, 2005.

[11] Martell, D. L., "Forest Fire Management," Handbook Of Operations Research In Natural Resources, International Series in Operations Research and amp; Management Science Weintraub, A., Romero, C., Bjørndal, T. et al., eds., pp. 489-509: Springer US, 2007.

[12] Alexander, M. E., "Fire behaviour as a factor in forest and rural fire suppression," Forest Research in association with New Zealand Fire Service Commission and National Rural Fire Authority, Forest Research Bulletin, vol. 197, 2001.

[13] González-Cabán, A., Costs of firefighting mopup activities: US Dept. of Agriculture, Forest Service, Pacific Southwest Forest and Range Experiment Station, 1984.

[14] Donovan, G. H., and Brown, T. C., “An Alternative Incentive Structure for Wildfire Management on National Forest Land," Forest Science, vol. 51, no. 5, pp. 387-395, 2005.

[15] AFN, I., Monitorização e Avaliação do Plano Nacional de Defesa da Floresta Contra Incêndios, 2009/2010 - Relatório Final Preliminar, Autoridade Florestal Nacional, 2011.

[16] Fernandes, P. M., "Forest fires in Galicia (Spain): The outcome of unbalanced fire management," Journal of Forest Economics, vol. 14, no. 3, pp. 155-157, 2008.

[17] Resolução do Conselho de Ministros n. ${ }^{\circ}$ 65/2006, PNDFCI, 2006.

[18] Oliveira, T., "Relatório da visita ao Chile," Protecção Florestal, grupo Portucel Soporcel, 2011.

[19] Ahrens, M., Brush, Grass, and Forest Fires, 0877650357, National Fire Protection Association, Fire Analysis and Research Division, 2010.

[20] Pacheco, A. P., "Simulation Analysis of a Wildland Fire Suppression System," DEIG, Faculty of Engineering, University of Porto, 2011.

[21] ISA, "Plano Nacional de Defesa da Floresta Contra Incêndios, Um Presente para o Futuro (Vol I/II, Anexo 3)," Factos e Números, 2005.

[22] Pereira, M. G., Malamud, B. D., Trigo, R. M. et al., "The history and characteristics of the 1980-2005 Portuguese rural fire database," Nat. Hazards Earth Syst. Sci., vol. 11, no. 12, pp. 3343-3358, 2011. 